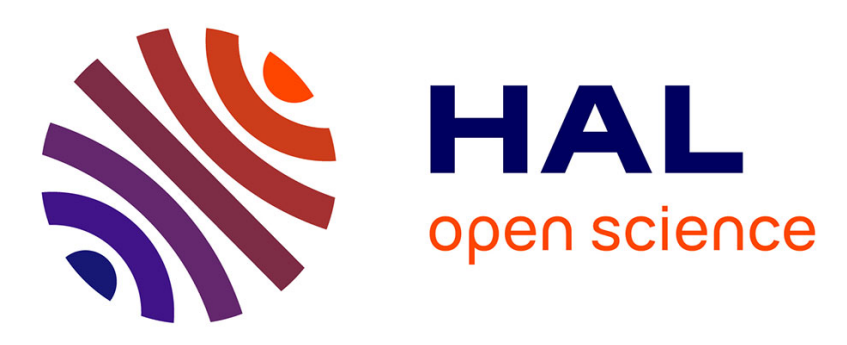

\title{
Substrate Integrated Waveguide Bandpass Filters implemented on Silicon Interposer for Terahertz Applications
}

Gaëtan Prigent, Anne-Laure Franc, Matthias Wietstruck, Mehmet Kaynak

\section{- To cite this version:}

Gaëtan Prigent, Anne-Laure Franc, Matthias Wietstruck, Mehmet Kaynak. Substrate Integrated Waveguide Bandpass Filters implemented on Silicon Interposer for Terahertz Applications. IEEE Internationnal Microwave Symposium, Jun 2020, Los Angeles, United States. 10.1109/IMS30576.2020.9223781 . hal-02948150

\author{
HAL Id: hal-02948150 \\ https://hal.laas.fr/hal-02948150
}

Submitted on 24 Sep 2020

HAL is a multi-disciplinary open access archive for the deposit and dissemination of scientific research documents, whether they are published or not. The documents may come from teaching and research institutions in France or abroad, or from public or private research centers.
L'archive ouverte pluridisciplinaire $\mathbf{H A L}$, est destinée au dépôt et à la diffusion de documents scientifiques de niveau recherche, publiés ou non, émanant des établissements d'enseignement et de recherche français ou étrangers, des laboratoires publics ou privés. 


\title{
Substrate Integrated Waveguide Bandpass Filters implemented on Silicon Interposer for Terahertz Applications
}

\author{
Gaetan Prigent $^{\# 1}$, Anne-Laure Franc ${ }^{\$}$, Matthias Wietstruck ${ }^{*}$, Mehmet Kaynak ${ }^{*}$ \\ \# LAAS-CNRS, University of Toulouse, CNRS, INP, Toulouse, France \\ \$ LAPLACE, University of Toulouse, CNRS, INP, Toulouse, France \\ *IHP, Frankfurt (Oder), Germany \\ ${ }^{1}$ gaetan.prigent@laas.fr
}

\begin{abstract}
This paper deals with the design of Substrate Integrated Waveguide (SIW) bandpass filter for D-band $(140 \mathrm{GHz})$ and terahertz $(280 \mathrm{GHz}$ and $420 \mathrm{GHz})$ applications. The filters are implemented in High Resistivity (HR) Silicon interposer technology provided by IHP foundry using Through Silicon Vias (TSV). Filters with $3 \mathrm{~dB}$ relative bandwidth of $5 \%$ and $10 \%$ are designed. A comparison of the filters performance is made for the different frequency range. It evidences the interest of SIW technology in sub-millimeter wave domain towards the resonator quality factor increase and, therefore, insertion loss reduction for filters.
\end{abstract}

Keywords-SIW, Filters, Si-based Integrated Passive Devices.

\section{INTRODUCTION}

The use of the electromagnetic spectrum below $30 \mathrm{GHz}$ has been highly developed for many industrial applications in recent years. However, the spreading of radio resources is progressing due to the proliferation of various terminals and diversification needs in these frequency ranges. In addition, we are getting into a new communication era with the future arrival of the $5 \mathrm{G}$ standards and the emergence of new applications such as the Internet of Things (IoT). Within this context, wireless communications will continue to play an increasingly important role. It is essential to develop wireless technologies capable to increase their capacity and speed of communication and, therefore, increased bandwidth is required. Thus, it is necessary to consider new radio resources. In recent studies data transmissions between fixed network base stations (backhaul network) are considered in D-band at $120 \mathrm{GHz}$ and $140 \mathrm{GHz}$.

Terahertz waves are still underutilized, especially because of the atmospheric absorption that strongly reduces transmission distances. It exists a frequency range in G-band between $195 \mathrm{GHz}$ and $315 \mathrm{GHz}$ for which atmospheric absorption is weak [1] (Fig. 1). The frequency band above $275 \mathrm{GHz}$ has not been allocated yet [2]-[3] but its use is envisaged in the international organizations for future standards [4], in particular for broadband communications $(>100 \mathrm{~Gb} / \mathrm{s}$ ) [5] (Figure 2) to address high data rate applications such as, machine to machine (M2M) wireless network for communication between data centres, short range fixed wireless access or kiosk downloading [6] for instance.

Within this telecommunication context, the filtering aspect is primary. However, the design of narrow-band planar filters appears as one of the most critical point. In view of the required selectivity levels, designers are, indeed, faced with problems related to control in the design, i.e., modelling accuracy, as well as the high insertion-loss levels inherent in such devices. Moreover, according to the low electrical lengths involved in millimetre and sub-millimetre wave, technological dispersion has to be as low as possible. This is especially important when the frequency range tends to $\mathrm{THz}$ domain. Planar filters have already been designed in D-bands $(110 \mathrm{GHz}-180 \mathrm{GHz})$ and at beyond. Considering the mmwave domain as well as the constraints on the insertion loss of the filter, most of them were implemented in III-V planar technologies [7]-[10]. However, given the improved performance of the integrated active components and their low production cost, silicon technologies have become attractive and essential for the realization of system on chips.

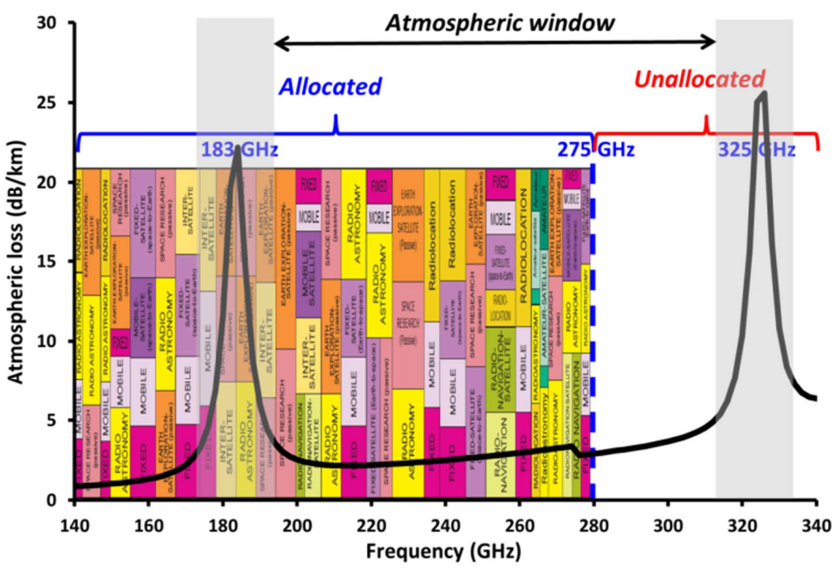

Fig. 1. Atmospheric loss [1] and band allocation [2]-[3] for millimetre-wave applications in G-band.
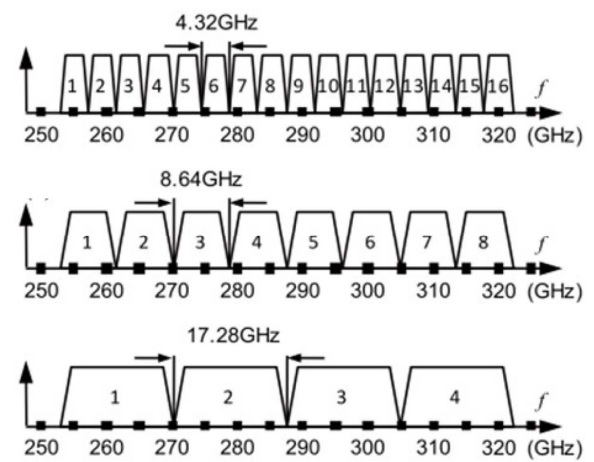

Fig. 2. Possible band allocation above $275 \mathrm{GHz}$. 
The main drawbacks of silicon technologies concerns dielectric loss which limits their use for narrow-band bandpass filters. Si-based filters are therefore implemented on technologies that annihilate loss effects due to silicon, either Silicon-on-Insulator technologies [11]-[12], above IC technologies such as Si-BCB [13]-[15] or in the back-end-ofline (BEOL) of Bi-CMOS technologies [16]. Thereby, Silicon-based technologies have attained performance equivalent to those of III-V technologies. Nevertheless, the low quality factors associated with planar technologies limit the improvement in the device performance.

The use of substrate integrated waveguide (SIW) allows increasing the quality factor of the filter resonators, and therefore its insertion loss [17]. In addition, it overcomes the limitations associated with transmission line dimensions due to short wavelengths, and therefore the frequency limitation of integrated passive devices (IPD). The use of SIW technologies have already been proposed in G-band using LTCC technologies [18]-[19] or air-filled SIW on silicon [20]-[21]. However, the use of low dielectric constant led to bulky filters which are not compatible with system integration.

The filters designed in this paper were developed in SIW technology implemented in high resistivity silicon interposer using Through Silicon Vias (TSV) technology proposed by IHP. The filters were designed at three operating frequencies $140 \mathrm{GHz}, 280 \mathrm{GHz}$ and $420 \mathrm{GHz}$ with 5\%- and 10\%-relativebandwidth.

\section{DESIGN OF SIW FILTER}

\section{A. Interposer Technology}

The filters were implemented in rectangular SIW embedded in thin Silicon substrate $(70 \mu \mathrm{m})$. The main difficulty when designing rectangular waveguides concerns the implementation of the metallized via-holes needed for lateral electrical walls or septum definition. Indeed, considering the very high frequency range, the required shape factor must be as high as possible while ensuring a good control of their position and dimension. Thereby, through Silicon Vias (TSVs) technology provided by IHP was used. It allows defining TSVs with fixed dimensions of $3 \mu \mathrm{m}$ wide for $50 \mu \mathrm{m}$ long and $70 \mu \mathrm{m}$ of height. This technology allows implementing planar metal in any layer of the silicon oxide BEOL. In the present work only $2 \mu \mathrm{m}$-thick metal layer (TM1) was addressed (Fig. 3-a). The TSVs are composed of $70 \mu \mathrm{m}$ Tungsten and $300 \mathrm{~nm}$ silicon oxide for substrate isolation layer. The minimum dimension between two TSVs is set to $5 \mu \mathrm{m}$. TSVs orientation can be vertical, horizontal or both.

\section{B. Filter topology and synthesis}

The SIW filters designed hereafter are $4^{\text {th }}$-order with three operating frequencies $140 \mathrm{GHz}, 280 \mathrm{GHz}$ and $420 \mathrm{GHz}$. A $20 \mathrm{~dB}$ in-band return loss is considered. Two relative bandwidths of $5 \%$ and $10 \%$ were investigated except for $140 \mathrm{GHz}$. Indeed, considering the large bulk at low frequency range, the filter with $140 \mathrm{GHz}$ central frequency was only designed with $10 \%$ bandwidth.

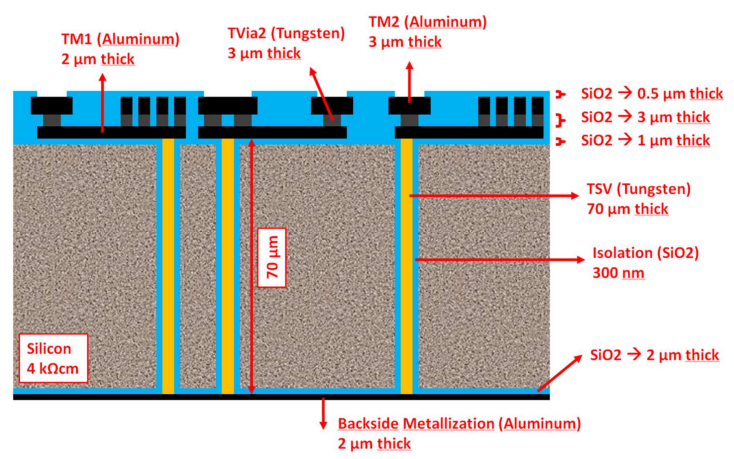

(a)

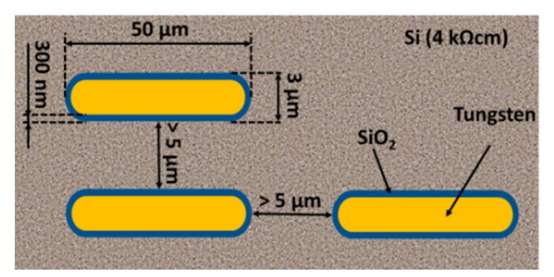

(b)

Fig. 3. Technological description of TSVs technology provided by IHP: technological benchmark (a), TSVs dimensioning (b).

The design technique used is based on the synthesis method proposed in [22]. It consists on defining a normalized coupling matrix between the filter resonators. The aim of this work is a proof of feasibility of the implementation of SIW filter on Silicon interposer technology. Therefore, a very simple coupling scheme was considered, without any cross coupling. The normalized values of the folded coupling matrix are given in (1).

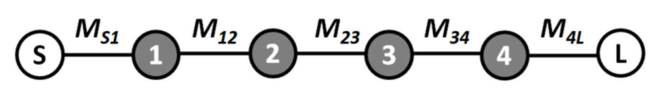

Fig.4. $4^{\text {th }}$-order filter coupling scheme.

$$
M=\left(\begin{array}{ccccccc} 
& \boldsymbol{S} & \mathbf{1} & \mathbf{2} & \mathbf{3} & \mathbf{4} & \boldsymbol{L} \\
\boldsymbol{S} & 0 & 1.035 & 0 & 0 & 0 & 0 \\
\mathbf{1} & 1.035 & 0 & 0.91 & 0 & 0 & 0 \\
\mathbf{2} & 0 & 0.91 & 0 & 0.699 & 0 & 0 \\
\mathbf{3} & 0 & 0 & 0.699 & 0 & 0.91 & 0 \\
\mathbf{4} & 0 & 0 & 0 & 0.91 & 0 & 1.035 \\
\boldsymbol{L} & 0 & 0 & 0 & 0 & 1.035 & 0
\end{array}\right)
$$

The denormalized coupling coefficient values, function of the relative bandwidth $\Delta$ are given by (2):

$$
C_{i j}=M_{i j} \cdot \Delta
$$

The filters are implemented in rectangular waveguide technology. In the design of a SIW transmission line to operate at a given frequency, there are three main design parameters that need to be considered. There are namely, the width of the SIW, the diameter of the metallic via-holes and the pitch between the metallic via-holes. Considering the technology used, the length of the TSVs are long compared to 
the wavelength. Thus, the SIW transmission line is effectively reduced to a dielectric filled rectangular waveguide, without electromagnetic energies leaking or radiating out between the metallic posts.

The width $(a)$ of the waveguide governs the cut-off frequencies of the propagating mode in the transmission line. It was fixed to promote single-mode $\left(\mathrm{TE}_{10}\right)$ propagation in the SIW using equation (3). Moreover, so as to minimize the waveguide attenuation, the operating frequency $f_{0}$ is set in the middle of the single-mode band, i.e. $\left[f_{T E_{10}}, f_{T E_{20}}\right]$. The length $(L)$ of the cavity is chosen to obtain a resonant frequency at $f_{0}$ for the dominant mode $\mathrm{TE}_{101}$, given by (5).

$$
\begin{aligned}
& f_{T E_{10}}=\frac{c_{0}}{2 a \sqrt{\varepsilon_{r}}} \\
& f_{T E_{20}}=\frac{c_{0}}{a \sqrt{\varepsilon_{r}}} \\
& f_{T E_{101}}=\frac{c_{0}}{2 \sqrt{\varepsilon_{r}}} \sqrt{\frac{1}{a^{2}}+\frac{1}{L^{2}}}
\end{aligned}
$$

Coupling coefficients in (1) are positive; it corresponds to a magnetic coupling. It was made using inductive irises which dimensions were calculated using electromagnetic simulations performed with Ansys-HFSS. The method consists in simulating two coupled cavities and extracting the two resonant frequencies $f_{a}$ and $f_{b}\left(f_{b}>f_{a}\right)$ as a function of the iris width [23]. The coupling coefficient is then evaluated using the following equation:

$$
C_{a b}=\frac{f_{b}^{2}-f_{a}^{2}}{f_{b}{ }^{2}+f_{a}^{2}}
$$

The simulation results (Figs. 5-7) show the interest of the SIW technology for the implementation of $\mathrm{THz}$ functions. Indeed, in addition to the substantial reduction in the size of the filters, a sharp increase in the quality coefficient is observed. Thus, for a bandwidth of $10 \%$, the insertion losses simulated with HFSS are $3.5 \mathrm{~dB}, 2.7 \mathrm{~dB}$ and $2 \mathrm{~dB}$ respectively for central frequencies of $140 \mathrm{GHz}, 280 \mathrm{GHz}$ and $420 \mathrm{GHz}$. For a relative bandwidth of $5 \%$ the insertion loss goes from $4.5 \mathrm{~dB}$ to $2.5 \mathrm{~dB}$ respectively for central frequencies of $280 \mathrm{GHz}$ and $420 \mathrm{GHz}$.

\section{RESULTS}

The filters were fabricated on the three bands concerned; only the measurements at $140 \mathrm{GHz}$ and $280 \mathrm{GHz}$ were carried out. Indeed, as the $420 \mathrm{GHz}$ measurements require a particular measurement procedure, the measurements have not been made yet. Nevertheless, regardless the results obtained for the other frequency bands (Figures 5-6) which are in very good agreement with the simulations, experiment results at $420 \mathrm{GHz}$ should meet the simulation results. Indeed, whatever the filters and the frequency range, a frequency shift of less than $1 \%$ is observed regardless of the operating frequency. A post-simulation has been carried out, it evidenced that the frequency shift can be explained by an underestimation of the thickness of the $\mathrm{Si}+\mathrm{SiO}_{2}$ layer. One should have considered
$73 \mu \mathrm{m}$ substrate thickness instead of $70 \mu \mathrm{m}$. However insertion loss levels are generally conserved. Thus, measured losses are $3.9 \mathrm{~dB}$ and $2.5 \mathrm{~dB}$ respectively at $140 \mathrm{GHz}$ and $280 \mathrm{GHz}$ for filters with $10 \%$ relative bandwidth and $4.5 \mathrm{~dB}$ for the $280 \mathrm{GHz}$ filter with $5 \%$ bandwidth.

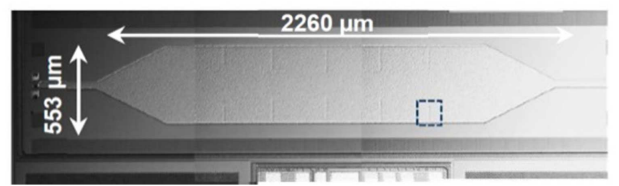

(a)

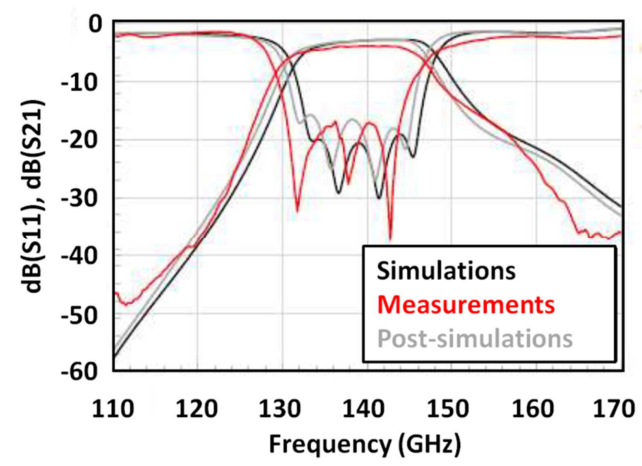

(b)

Fig.5. $140 \mathrm{GHz} 4^{\text {th }}$-order SIW filter with $10 \%$ relative-bandwidth: (a) photography and (b) simulated (HFSS) and measured results.

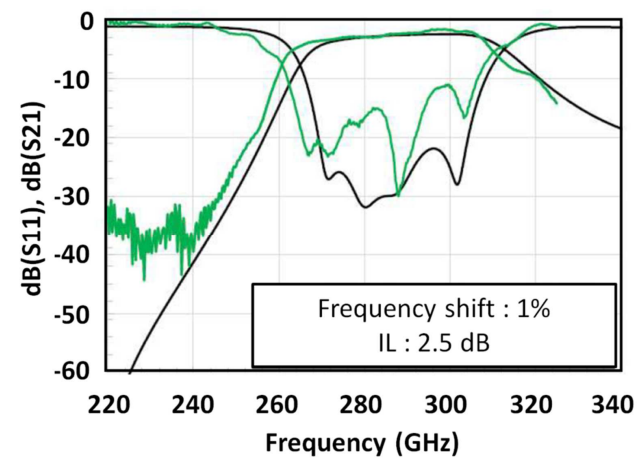

(a)

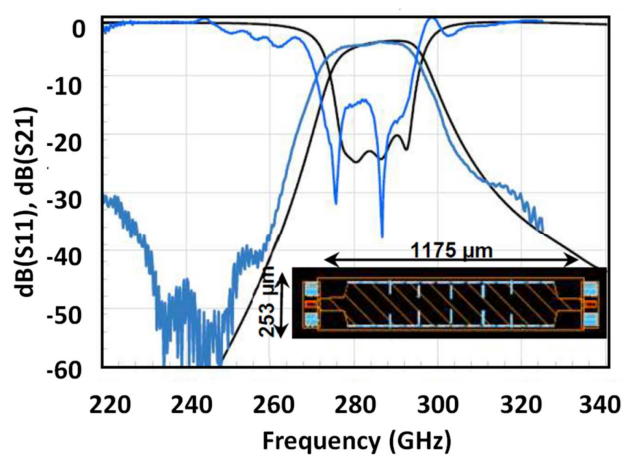

(b)

Fig.6. Simulation (HFSS) and measurement results of the $280 \mathrm{GHz} 4^{\text {th }}$-order SIW filter with: (a) 10\%- and (b) 5\%-relative bandwidth. 


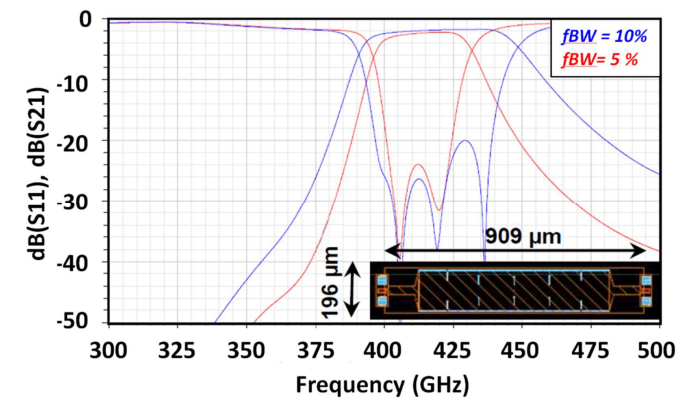

Fig.7. Simulation (HFSS) results of the $420 \mathrm{GHz} 4^{\text {th }}$-order SIW filter with: $10 \%$ - and 5\%-relative bandwidth.

The electrical performance of the different filters is summarized in Table 1. It highlights the interest of SIW technologies for implementation of bandpass filters in the $\mathrm{THz}$ domain. Indeed, the estimated quality factor $Q$ increases with the frequency and, consequently, the insertion loss of the filter decreases. Moreover, contrary to low frequency range, the difference between insertion loss of narrowband and mediumband bandpass filters fade as the frequency increases. Henceforth, this allows considering the implementation of narrowband filter while limiting the impact on insertion losses.

Table 1 . Comparison of $4^{\text {th }}$-order SIW filters electrical performance

\begin{tabular}{cccc}
\hline $\begin{array}{c}\text { Fractional } \\
\text { Bandwidth }\end{array}$ & $\begin{array}{c}f_{0}=140 \mathrm{GHz} \\
\text { Measured }\end{array}$ & $\begin{array}{c}f_{0}=280 \mathrm{GHz} \\
\text { Measured }\end{array}$ & $\begin{array}{c}f_{0}=420 \mathrm{GHz} \\
\text { Simulated }\end{array}$ \\
\hline \hline $10 \%$ & $I L=3.9 \mathrm{~dB}$ & $I L=2.5 \mathrm{~dB}$ & $I L=1.9 \mathrm{~dB}$ \\
& $Q \cong 89$ & $Q \cong 139$ & $Q \cong 183$ \\
\hline $5 \%$ & - & $I L=4.5 \mathrm{~dB}$ & $I L=2.2 \mathrm{~dB}$ \\
& - & $Q \cong 119$ & $Q \cong 225$ \\
\hline
\end{tabular}

\section{CONCLUSION}

D-band $(140 \mathrm{GHz})$ and $\mathrm{THz}(280 \mathrm{GHz}, 420 \mathrm{GHz})$ filters were developed in SIW technology on a high resistivity silicon substrate using IHP's TSV techniques. The performances obtained proved the interest of these topologies to address $\mathrm{THz}$ bands especially for the improvement of insertion loss levels. The excellent agreement obtained with the simulations attests to the quality of the technological process developed by IHP as well as the design method used. According to these promising results, more complex filters can be investigated using cross-coupled resonators for out-ofband response improvement, as well as multiplexer implementation.

\section{REFERENCES}

[1] https://smiles-p6.nict.go.jp/thz/en/decay_e.html

[2] https://www.ntia.doc.gov/page/2011/united-states-frequencyallocation-chart

[3] https://www.anfr.fr/gestion-des-frequences-sites/tnrbf/frise-interactive/

[4] A. Kasamatsu, I. Osako, H. Ogawa, "Recent Standardization Activities in the Terahertz Communication Field, New Breeze, no 27-1, 2015

[5] M. Fujishima, S. Amakawa, "Integrated-circuit approaches to $\mathrm{THz}$ communications: Challenges, advances, and future prospects,” IEICE Trans. Fundamentals, vol. E100-A, no. 2, pp. 516 - 523, Feb. 2017
[6] T. Kürner, IEEE 802.15-10-0320-02-0000-Tutorial_Igthz.

[7] G. Prigent, E. Rius, K. Blary, H. Happy, S. Lepilliet, G. Dambrine, A Cappy, "Design of Narrow Band-pass Planar Filters for MillimeterWave Applications up to $220 \mathrm{GHz}$ ", IEEE International Microwave Symposium, Long Beach, CA, USA, 2005

[8] G. Wolf, G. Prigent, E. Rius, S. Demichel, R. Leblanc, G. Dambrine, H Happy, "Band-pass coplanar filters in the G-frequency band," IEEE Microwave and Wireless Component Letters, vol. 15, no. 11, pp. 799801, Nov. 2005.

[9] D. Stephens, P. R. Young and I. D. Robertson, "Millimeter-wave substrate integrated waveguides and filters in photoimageable thickfilm technology," IEEE Transactions on Microwave Theory and Techniques, vol. 53, no. 12, pp. 3832-3838, Dec. 2005.

[10] C. J. Hwang, L.B. Lok, I.G. Thayne, K. Elgaid "Parallel coupled-line bandpass filter with branch-line shape for G-band frequency", Electronic Letters, vol. 45, no 9, 2009.

[11] G. Prigent, F. Gianesello, D. Gloria, C. Raynaud, "BandPass Filter for Millimeter-Wave Applications up to $220 \mathrm{GHz}$ integrated in advanced thin SOI CMOS technology on High Resistivity substrate", Proceedings EuMA, Vol. 4, no 2, pp118-123, June 2008.

[12] F. Gianesello, D. Gloria. S. Montusclat, C. Raynaud, S. Boret, G. Dambrine, S. Lepilliet, B. Martineau, R. Pilard, "1.8 dB insertion loss $200 \mathrm{GHz}$ CPW band pass filter integrated in HR SOI CMOS Technology," IEEE International Microwave Symposium, Honolulu, HI, USA, 2007, pp. 453-456, 2007

[13] G. Prigent, E. Rius, F. Le Pennec, S. Le Maguer, C. Quendo, G. Six, H. Happy, "Design of Narrow-Band DBR Planar Filters in Si-BCB Technology for Millimeter-Wave Applications", I.E.E.E. Transactions on Microwave theory and techniques, Vol. 52, no 3, pp 1045-1051, March 2004.

[14] S. Shi, Y. Zhang, D. Zhou. R. Yue, Y. Wang, "Design of $140 \mathrm{GHz}$ Narrow Band-pass Planar Filters Based on Open Loop Resonators", 2019 International Conference on IC Design and Technology, June 2019

[15] R. Li, T. G. Lim, S. W. Ho, Y. Z. Xiong, D. Pinjala, "Design of wideband bandpass filters using Si-BCB technology for millimeterwave applicationsElectronic Components and Technology Conference, 2010

[16] P. Rynkiewicz, A.L. Franc, F. Coccetti, M. Wietstruck, M. Kaynak, G. Prigent, "2nd- And 4th-order Planar Dual-Mode Ring Filters at 140 $\mathrm{GHz}$ in a 130nm BiCMOS Technology", IEEE Asia Pacific Microwave Conference (APMC), November 2017.

[17] Y. Cassivi, L. Perregrini, K. Wu, G. Conciauro, "Low-Cost and High-Q Millimeter-Wave Resonator Using Substrate Integrated Waveguide Technique", IEEE European Microwave Week, 2002

[18] K. Wang, S. W. Wong, G. H. Sun, Z. N. Chen, L. Zhu, and Q. X. Chu, "Synthesis Method for Substrate-Integrated Waveguide Bandpass Filter With Even-Order Chebyshev Response," IEEE Trans. on Component, Packaging. and Manufacturing Technology, vol. 6, no. 1, pp. 126-135, Jan. 2016.

[19] A. H. Khalil, D. Passerieux, D. Baillargeat, N. Delhote, S. Verdeyme, L. Estagerie, and J. Puech, "Quasi-elliptic and Chebyshev compact LTCC multi-pole filters functioning in the submillimetric wave region at 150 GHz," IEEE Trans. Microw. Theory Tech., vol. 58, no. 12, pp. 3925 3935, Dec. 2010

[20] Y. Li, L.-A. Yang, L. Du, K. Zhang, Y. Hao, "Design of MillimeterWave Resonant Cavity and Filter Using 3-D Substrate-Integrated Circular Waveguide", IEEE Microwave and Wireless Components Letters, Vol. 27, no. 8, 2017

[21] J. Cui, C. Ai, Y. Zhang, J. Hu, B. Yan, R. Xu, “ A 420 GHz Waveguide Filter Based on MEMS Technology”, IEEE International Microwave Symposium, 2017

[22] Richard J. Cameron, "General Coupling Matrix Synthesis Methods for Chebyshev Filtering Functions.", IEEE Transactions on Microwave Theory and Techniques, vol. 47, N4, April 1999

[23] X. Chen, W. Hong, T. Cui, J. Chen, K. Wu, "Substrate Integrated Waveguide (SIW) Linear Phase Filter", IEEE Microwave and Wireless Components letters, vol 15, no 11, 2005 